\title{
Chelation therapy for secondary neonatal iron over load: Lessons learned from rhesus hemolytic disease
}

\author{
Fareed Khdair-Ahmad ${ }^{1}$, Tariq Aladily ${ }^{2}$, Olfat Khdair-Ahmad ${ }^{3}$, Eman F. Badran ${ }^{4}$ \\ ${ }^{1}$ Section of Pediatric Gastroenterology, ${ }^{2}$ Department of Pathology, ${ }^{3}$ Department of Pediatrics and ${ }^{4}$ Section of Neonatology, \\ School of Medicine, The University of Jordan, Amman, Jordan, E-mail: fareedpeds@yahoo.com \\ Received: 28th March 2017, Revised: 31st May 2017, 12th June 2017, Accepted: 30th June 2017
}

SUMMARY: Khdair-Ahmad F, Aladily T, Khdair-Ahmad O, Badran EF. Chelation therapy for secondary neonatal iron overload: Lessons learned from rhesus hemolytic disease. Turk J Pediatr 2018; 60: 335-339.

Secondary neonatal iron overload occurs with intrauterine and post-natal blood transfusions. Treatment with intravenous Deferoxamine was reported only in four cases in the literature. Herein we report a case of a patient born at 36 weeks of gestation, who had rhesus hemolytic disease. He developed secondary iron overload, causing liver injury, after a total of six blood transfusions: four intrauterine and 2 post-natal transfusion therapies. Intravenous Deferoxamine treatment was started at the age of 45 days due to a ferritin level of 40,000 $\mu \mathrm{g} / \mathrm{L}$, progressive rise of liver enzymes, and worsening cholestasis. Treatment resulted in marked reduction in ferritin level (down to $829 \mu \mathrm{g} / \mathrm{L}$ at the age of 6 months), significant improvement in the liver enzymes, and resolution of cholestasis.

Key words: cholestasis, iron overload, deferoxamine, neonates, intrauterine blood transfusion therapy.

Secondary iron overload in neonates occurs due to frequent iatrogenic blood transfusions or secondary to neonatal hemolytic diseases, such as rhesus hemolytic disease (RHD). ${ }^{1}$ Despite the wide use of anti-D immunoglobulin during pregnancy, $\mathrm{Rh}$-isoimmunization still occurs in some parts of the world, with subsequent hydrops and stillbirths. Intrauterine transfusions (IUT) have been used in the management of such severe cases of intrauterine anemia. ${ }^{2}$ Several studies have discussed the neonatal outcomes for RHD patients who underwent IUTs $^{3,4}$, with the associated complications, like liver injury, cholestasis and hypo-regenerative anemia. Yet, only four reports addressed the use of chelation therapy for the treatment of secondary iron overload in this patient group. ${ }^{5-8}$

\section{Case Report}

A 2290 g male patient was born at 36-week gestation to a 28-year-old mother, gravida 3, para 2. Her blood group was AB negative, and the father's blood group was A positive. There was no consanguinity between the parents. Her first baby was born after a term of uncomplicated pregnancy, during which she did not receive anti-D. Her second baby died in the neonatal intensive care unit at three hours of age due to severe $\mathrm{Rh}$ - isoimmune hemolytic anemia.

During her current pregnancy, the fetus received four intrauterine blood transfusions. These were started at 22 weeks of gestation and were repeated every 4 weeks. Fetal hemoglobin before each transfusion ranged from 11$11.4 \mathrm{gm} / \mathrm{dl}$. A total amount of $260 \mathrm{ml}$ of $\mathrm{O} \mathrm{Rh}$ negative blood was transfused to the fetus, and the mother was given Intra venous Immunoglobulin (IVIG) twice during the second trimester. Fetal intrauterine Coombs test was repeatedly negative. The mother and her treating physician opted for regular transfusions to prevent sudden fatal intrauterine hemolysis.

At 36 weeks of gestation, the mother went into labor and delivered vaginally. APGAR score was 8 at the first minute and 9 at 5 minutes. No hydrops was noted at birth, and no hepatosplenomegaly or jaundice were present. 


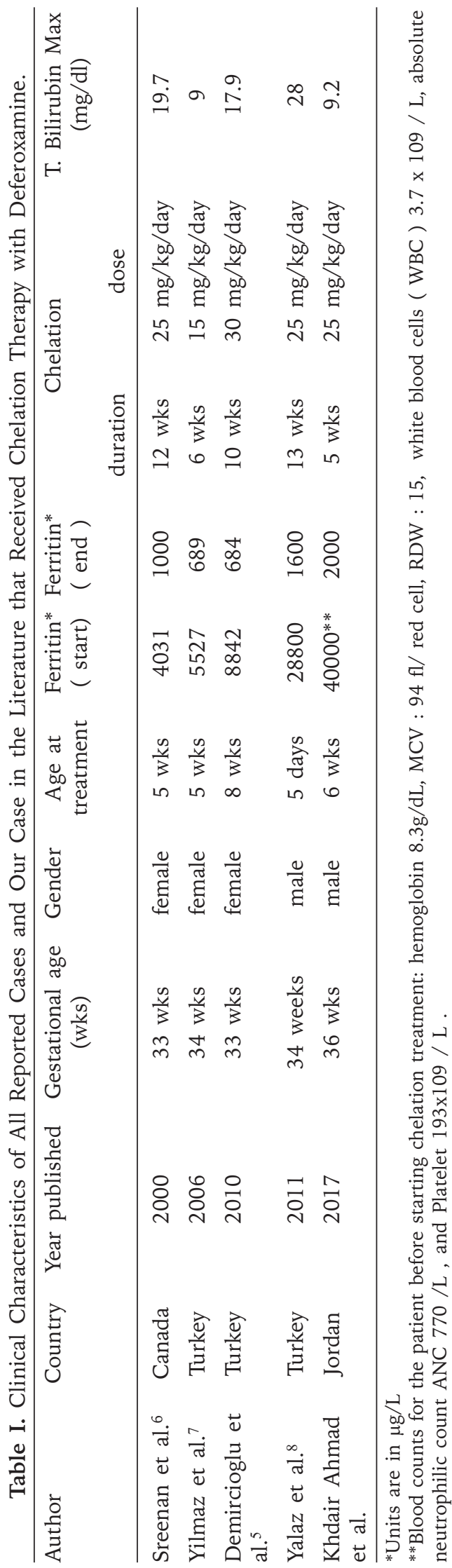

Cord blood bilirubin was $3.2 \mathrm{mg} / \mathrm{dl}$ (normal range less than $1.8 \mathrm{mg} / \mathrm{dl}$ ), patient blood group was $\mathrm{AB}$ positive, and direct Coombs test was negative. Hemoglobin at 4 hours of age was $13.7 \mathrm{~g} / \mathrm{dl}$ (normal range 14-18 mg/ dl).

Phototherapy was started at 12 hours of age and total serum bilirubin (TSB) was $7.8 \mathrm{mg} / \mathrm{dl}$ (normal range less than $7 \mathrm{mg} / \mathrm{dl}$ ). The patient did not receive IVIG, and did not need blood exchange or blood transfusions initially. Serial hemoglobin level measurements showed stable values ranging from 13.7 to $13.9 \mathrm{~g} / \mathrm{dl}$.

Patient was discharged and sent home on the fifth day of life, with TSB of $8.4 \mathrm{mg} / \mathrm{dl}$, Direct Serum Bilirubin (DSB) $6 \mathrm{mg} / \mathrm{dl}$, and alanine aminotransferase (ALT) $22 \mathrm{U} / \mathrm{L}$ (normal range 3-35). Weekly follow-up in the clinic was arranged.

At the age of 11 days, hemoglobin was 10.8 $\mathrm{g} / \mathrm{dl}$, TSB $6.8 \mathrm{mg} / \mathrm{dl}$, DSB $5 \mathrm{mg} / \mathrm{dl}$, and ALT 47U/L. Ferritin level was not checked. He was started on iron, folic acid, and erythropoietin. A week later, ALT was found to be $77 \mathrm{U} / \mathrm{L}, \mathrm{DSB}$ $6.12 \mathrm{mg} / \mathrm{dl}$, TSB $6.97 \mathrm{mg} / \mathrm{dl}$, and ferritin level was found to be high at $4000 \mu \mathrm{g} / \mathrm{L}$ (normal range $25-200 \mu \mathrm{g} / \mathrm{L}$ ), so iron was discontinued.

At the age of 26 days, the patient presented to the emergency room with irritability. Investigations showed low hemoglobin at $4.7 \mathrm{~g} / \mathrm{dl}$, so he was admitted to the neonatal intensive care unit and was transfused with $\mathrm{O}$ negative blood, which is compatible with his and his mother's blood groups. This top-up transfusion was done twice, with $10 \mathrm{ml} / \mathrm{kg}$ and $15 \mathrm{ml} / \mathrm{kg}$. ALT was $80 \mathrm{U} / \mathrm{L}$, and aspartate aminotransferase (AST) was $140 \mathrm{U} / \mathrm{L}$ (normal 5-45). Gamma-glutamyl transferase (GGT) was $90 \mathrm{U} / \mathrm{L}$ (normal 70-180), ferritin was 5623 $\mu \mathrm{g} / \mathrm{L}$, and TSB with DSB were $6.7 \mathrm{mg} / \mathrm{dl}$ and $6.1 \mathrm{mg} / \mathrm{dl}$, respectively. Direct Coombs test was negative. There was no evidence of neonatal liver failure: serum Albumin level, coagulation profile, and serum glucose were all normal.

Liver ultrasound was normal. Other causes of liver injury were excluded by testing for TORCH, parvovirus B19, EBV, hepatitis A, B and $\mathrm{C}$, alpha-1 antitrypsin, hemophagocytic lymphohistiocytosis (HLH) and metabolic causes. Testing for HLH included normal triglyceride and fibrinogen levels, and normal bone marrow aspirate. 


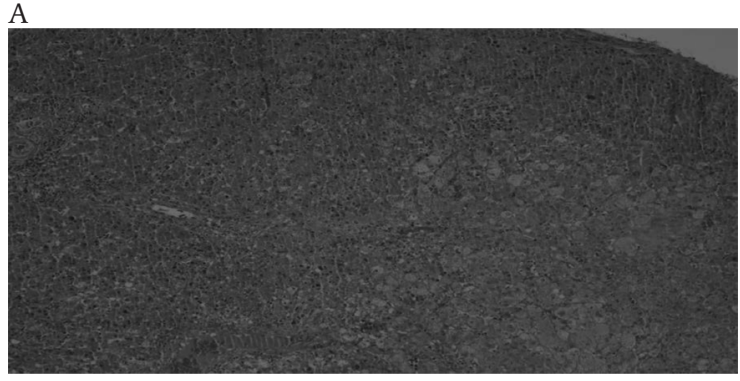

B

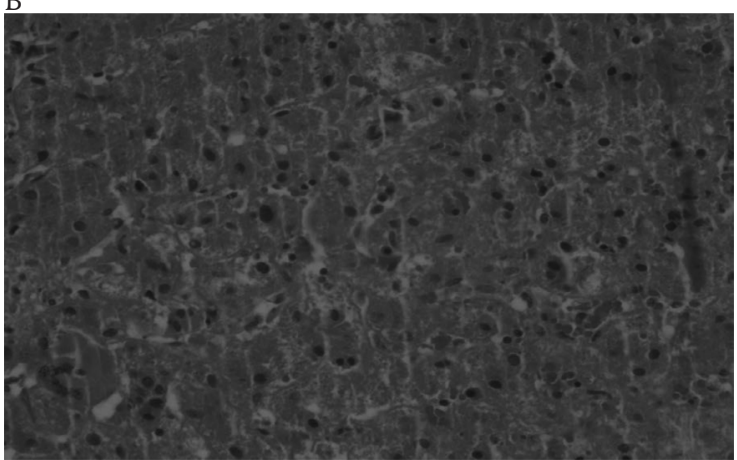

Fig. 1. Liver biopsy, hematoxylin and eosin stain: moderately disturbed hepatic architecture and lobular disarray (A). The hepatocytes display feathery degeneration and ballooning with intracellular and canalicular cholestasis. Intact bile ducts (B)

A hepatobiliary iminodiacetic acid scan (HIDA scan) showed prompt uptake of the Technetium in the hepatic parenchyma, with no evidence of hepatic clearance into the gallbladder or bowel even after 24 hours. Intraoperative cholangiogram (IOC) showed a free passage of contrast into the intrahepatic biliary tree and into the small bowel. An open liver biopsy was done at the time of IOC. It showed (Fig. 1) moderately disturbed hepatic architecture and lobular disarray. The hepatocytes showed ballooning with intracellular and canalicular cholestasis. The bile ducts were intact. Special stain for alpha-1 antitrypsin globule was negative. Pearl's special stain (Fig. 2) showed increased deposition of iron aggregates around the portal and central vein areas. Abdomen magnetic resonance image showed iron deposits in the liver only.

The impression at that point was secondary iron overload, due to hemolysis and blood transfusions, causing liver injury, which manifested as elevation of liver enzymes and direct hyperbilirubinemia. Due to rising liver enzymes, with worsening of cholestasis, the patient was admitted for chelation therapy

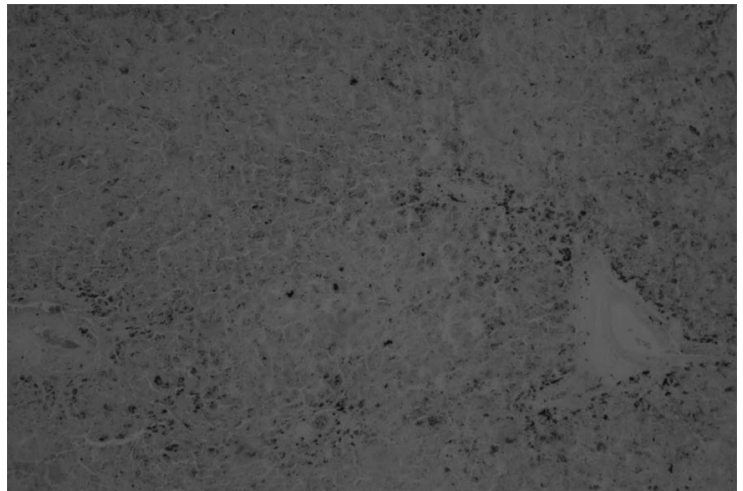

Fig. 2. liver biopsy with Pearl's stain

Pearl's special stain shows increase deposition of iron aggregates around the portal and central vein areas.

at the age of 45 days. Baseline laboratory investigations before starting intravenous Deferoxamine treatment were: ALT $266 \mathrm{U} / \mathrm{L}$, AST 593U/L, GGT $90 \mathrm{U} / \mathrm{L}$, TSB $9.2 \mathrm{mg} / \mathrm{dl}$, DSB $8.5 \mathrm{mg} / \mathrm{dl}$, GGT $90 \mathrm{U} / \mathrm{L}$, ferritin $40.000 \mu \mathrm{g} / \mathrm{L}$, hemoglobin $8.3 \mathrm{~g} / \mathrm{dl}$, white blood cells (WBC) $3.7 \times 10^{9} / \mathrm{L}$, absolute neutrophilic count ANC $770 / \mathrm{mm}^{3}$, platelet $193 \times 10^{9} / \mathrm{L}$. He received 5 cycles of deferoxamine, with a dose of $25 \mathrm{mg} /$ $\mathrm{kg} /$ day for 5 days per week over 5 weeks. The patient was given a "treatment holiday" for 2 days each cycle to decrease the side effect of the treatment.

At the end of treatment, liver functions were: ALT $143 \mathrm{U} / \mathrm{L}$, AST 187U/L, GGT 110.8U/L, TSB $7.06 \mathrm{mg} / \mathrm{dl}$, DSB $6.03 \mathrm{mg} / \mathrm{dl}$, with ferritin $2000 \mu \mathrm{g} / \mathrm{L}$, hemoglobin $12.8 \mathrm{~g} / \mathrm{dl}$, WBC 12.3 x $10^{9} / \mathrm{L}$, ANC $5430 / \mathrm{mm}^{3}$, and platelet $281 \mathrm{x}$ $10^{9} / \mathrm{L}$. Erythropoietin was continued during hospitalization. Hearing screen was normal before discharging home.

Liver enzymes normalized at the age of 6 months. ALT was $38 \mathrm{U} / \mathrm{L}$, AST $44 \mathrm{U} / \mathrm{L}$, TSB 0.3 $\mathrm{mg} / \mathrm{dl}$, and DSB $0.1 \mathrm{mg} / \mathrm{dl}$; ferritin decreased significantly to $829 \mu \mathrm{g} / \mathrm{L}$, hemoglobin was $11.8 \mathrm{~g} / \mathrm{dl}$, WBC $8.54 \times 10^{9} / \mathrm{L}$, ANC $2305 / \mathrm{mm}^{3}$, platelet $241 \times 10^{9} / \mathrm{L}$. The patient was doing well at that time, with a normal physical examination.

The parents of the patient consented to use the data for publication.

\section{Discussion}

Cholestatic jaundice affects around 1 in every 2500 term infants, and it indicates a primary 
liver problem. ${ }^{9}$ Yet it is crucial to make the accurate diagnosis in a timely manner since some of the treatments offered are time sensitive. ${ }^{9}$ The differential diagnosis list for this condition is wide where primary and secondary iron overload (hemochromatosis) take the lead.

Primary neonatal hemochromatosis, or what is now widely referred to as gestational alloimmune liver disease (GALD), is a nonhereditary disease causing liver injury in neonates and infants and results in extrahepatic siderosis. ${ }^{10}$ It is thought to be due to a yet unspecified fetal antigen that triggers the mother's immune system and results in IgGmediated liver injury in the fetus. ${ }^{10}$ Iron deposition in the tissue is the result of hepatic tissue damage rather than the cause of it. GALD can be severe and, if not treated, fatal. A key point in the diagnosis is the proof of extrahepatic deposition of iron, either in the buccal mucosal biopsy or in any abdominal organ, like the pancreas, through magnetic resonance (MRI) imaging. Treatment regimen includes the usage of exchange transfusion and IVIG. Our patient's MRI showed iron deposition in the liver only.

Secondary iron overload in neonates occurs due to frequent iatrogenic blood transfusions or secondary to neonatal hemolytic diseases, such as RHD. ${ }^{1}$ Despite the wide use of anti-D immunoglobulin during pregnancy, Rh-isoimmunization still occurs in some parts of the world, with secondary hydrops fetalis and intrauterine fetal demise. With the introduction of $\mathrm{IUT}^{2}$, the mortality and morbidities of RHD have declined, yet new issues have emerged, like secondary iron over load. ${ }^{3}$ The culprits for iron overload are hemolysis, IUT, and postnatal blood transfusions. Ferritin level is used as a surrogate for the iron level in the liver tissue. Several studies showed the incidence of cholestasis in neonatal hemolytic disease to be $13-20 \%$ of all patients. 3,4

To our knowledge, for neonates with RHD and cholestatic liver disease, there are only four case reports in the literature that reviewed a specific treatment. ${ }^{5-8}$ This consists of chelation therapy with the usage of intravenous Deferoxamine. Table I reviews these case reports and the related clinical data in comparison to our case. The cases included 3 females and 2 males, with our case being the oldest of them in terms of gestational age (36 weeks vs $33-34$ weeks). This reaffirms that prematurity is a factor that aggravates the severity of cholestasis in neonates. ${ }^{9}$

All of the cases, except one ${ }^{8}$, were treated with chelation therapy after 4 weeks of life. Currently, there are no specific guidelines regarding when to start chelation therapy. ${ }^{5}$ In all reported cases, the decision was based on clinical parameters: how sick the patient was, the rate of rise in liver enzymes, the degree of cholestasis, and the rate of ferritin level rise. The dose for intravenous Deferoxamine was variable (range $15-30 \mathrm{mg} / \mathrm{kg} /$ day). This shows that different doses can be given, as long as no complications from therapy are encountered. Higher doses might be given for patients with very high ferritin levels.

The duration of treatment was not the same for all cases. It ranged from 5 weeks to 13 weeks, with our patient being the one who had the shortest duration of treatment even though he was the one with the highest ferritin level before chelation. The decision on the duration of treatment in our patient was based on his clinical condition. The downward trend in his ferritin, ALT, AST and TSB helped to make that decision. Our patient might have benefited from the fact that he was a "late premature baby", and his body excretion of iron was, therefore, more enhanced with treatment. This certainly needs more reports and studies to confirm. The variation in the treatment durations points to the fact that the duration of chelation can be adjusted according to the clinical response, with the most important parameter to monitor being the ferritin level, along with the downward trend of ALT and AST. To stop chelation therapy, it is our experience that normal AST and ALT are not a prerequisite.

Leukopenia, being a complication of treatment, was reported in one case. ${ }^{8}$ Deferoxamine is known to cause other complications ${ }^{11-13}$, like visual and auditory neurotoxicity due to chronic treatment, and acute effects, including abdominal pain, diarrhea, nausea, vomiting, and hypotension. None of these were reported in these cases.

Hyporegenerative anemia is a known complication with RHD and IUT.4,14 Iron supplements with erythropoietin are, therefore, given. However, when iron overload is a 
concern, like in our case, iron supplement should be discontinued.

A multidisciplinary approach is crucial for the best outcome. This is best delivered by a team formed from all the involved specialties: Neonatology, pediatric gastroenterology, pediatric hematology, obstetrics and gynecology, and pathology. Coordinated care, proper communication with the parents and between caregivers, and close follow-up are key for successful management.

Secondary neonatal iron overload occurs with intrauterine and post-natal blood transfusions. It presents in the neonatal period but usually necessitates treatment after 1 month of life. Ferritin level and liver enzymes should be routinely checked and monitored in this patient group. When clinically indicated, intravenous Deferoxamine is a safe and effective method of treatment. A multidisciplinary approach is crucial.

\section{REFERENCES}

1. Aygun C, Tekinalp G, Gurgey A. Increased fetal iron load in rhesus hemolytic disease. Pediatr Hematol Oncol 2004; 21: 329-333.

2. Craparo FJ, Bonati F, Gementi P, Nicolini U. The effects of serial intravascular transfusions in ascitic/ hydropic RhD-alloimmunized fetuses. Ultrasound Obstet Gynecol 2005; 25: 144-148.

3. Smits-Wintjens VE, Rath ME, Lindenburg IT, et al. Cholestasis in neonates with red cell alloimmune hemolytic disease: Incidence, risk factors and outcome. Neonatology 2012; 101: 306-310.

4. FBadran E, Al-lawama M, Masri A, Al-Amouri I, Al Kazaleh F. Fetal intrauterine transfusion therapy: Neonatal outcomes. J Blood Lymph 2013; 3: 112.

5. Demircioglu F, Caglayan Sozmen S, Yilmaz S, et al. Severe iron overload and hyporegenerative anemia in a case with rhesus hemolytic disease: therapeutic approach to rare complications. Turk J Haematol 2010; 27: 204-208
6. Sreenan C, Idikio HA, Osiovich H. Successful chelation therapy in a case of neonatal iron overload following intravascular intrauterine transfusion. J Perinatol 2000; 20: $509-512$.

7. Yilmaz S, Duman N, Ozer E, et al. A case of rhesus hemolytic disease with hemophagocytosis and severe iron overload due to multiple transfusions. J Pediatr Hematol Oncol 2006; 28: 290-292.

8. Yalaz M, Bilgin BS, Koroglu OA, et al. Desferrioxamine treatment of iron overload secondary to $\mathrm{RH}$ isoimmunization and intrauterine transfusion in a newborn infant. Eur J Pediatr 2011; 170: 1457-1460.

9. Fawaz R, Baumann U, Ekong U, et al. Guideline for the Evaluation of Cholestatic Jaundice in Infants: Joint Recommendations of the North American Society for Pediatric Gastroenterology, Hepatology, and Nutrition and the European Society for Pediatric Gastroenterology, Hepatology, and Nutrition. J Pediatr Gastroenterol Nutr 2017; 64 :154-168.

10. Feldman AG, Whitington PF. Neonatal hemochromatosis. J Clin Exp Hepatol 2013; 3: 313-320.

11. Botzenhardt S, Li N, Chan EW, Sing CW, Wong IC, Neubert A. Safety profiles of iron chelators in young patients with haemoglobinopathies. Eur J Haematol 2017; 98: 198-217.

12. Mobarra N, Shanaki M, Ehteram H, et al. A Review on Iron Chelators in Treatment of Iron Overload Syndromes. Int J Hematol Oncol Stem Cell Res 2016; 10: 239-247.

13. Taher AT, Porter JB, Kattamis A, Viprakasit V, Cappellini MD. Efficacy and safety of iron-chelation therapy with deferoxamine, deferiprone, and deferasirox for the treatment of iron-loaded patients with nontransfusiondependent thalassemia syndromes. Drug Des Devel Ther 2016; 10: 4073-4078.

14. Thorp JA, O'Connor T, Callenbach J, et al Hyporegenerative anemia associated with intrauterine transfusion in rhesus hemolytic disease. Am J Obstet Gynecol 1991; 165: 79-81. 